\title{
Anionic starch-induced Cu-based composite with flake-like mesostructure for gas-phase propanal efficient removal
}

\author{
Chi He ${ }^{\mathrm{a}, *}$, Xiaohe Liu ${ }^{\mathrm{a}}$, Jianwen Shi ${ }^{\mathrm{b}}$, Chunyan Ma ${ }^{\mathrm{c}}$, Hua Pan ${ }^{\mathrm{a}, *}$, Guilin $\mathrm{Li}^{\mathrm{a}}$ \\ ${ }^{a}$ Department of Environmental Science and Engineering, School of Energy and Power Engineering, Xi'an Jiaotong University, Xi'an 710049, Shaanxi, China \\ ${ }^{\mathrm{b}}$ Center of Nanomaterials for Renewable Energy, State Key Laboratory of Electrical Insulation and Power Equipment, School of Electrical Engineering, Xi'an Jiaotong University, \\ Xi'an 710049, Shaanxi, China \\ ${ }^{\mathrm{c}}$ Department of Environmental Nano-materials, Research Center for Eco-Environmental Sciences, Chinese Academy of Sciences, Beijing 100085, China
}

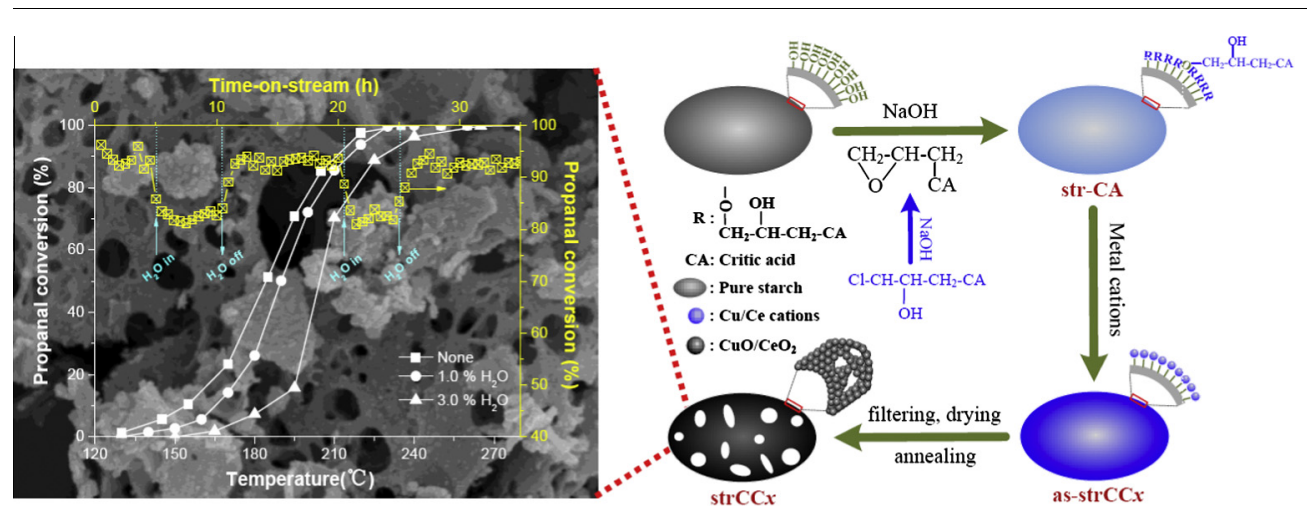

\section{A R T I C L E I N F O}

\section{Article history:}

Received 24 February 2015

Accepted 11 May 2015

Available online 21 May 2015

\section{Keywords:}

Catalytic oxidation

Chelating

Anionic starch

Mesoporous metal composite VOCs

\begin{abstract}
A B S T R A C T
Highly crystalline flake-like $\mathrm{CuCeO}_{2-\delta}$ composites ( $\operatorname{strCC} x$ ) with large specific surface area and developed mesoporosity were prepared using an economic and effective bio-template route. Modified starch with abundant surface carboxyl groups was adopted as the chelating agent and template for metal cations immobilization via electrostatic attraction predominately based on the process of $-\mathrm{COO}^{-} \ldots \mathrm{Cu}^{2+}$ and $-\mathrm{COO}^{-} \ldots \mathrm{Ce}^{3+}$. Physicochemical properties of prepared materials were systematically explored by FT-IR, XRD, TG, $\mathrm{N}_{2}$ adsorption/desorption, FE-SEM, TEM, $\mathrm{H}_{2}$-TPR, $\mathrm{O}_{2}$-TPD, XPS, DRUV-Vis, and XAFS techniques. Propanal as a typical oxygen-contained VOC was adopted as the probe pollutant to evaluate the catalytic performance of synthesized materials. Characterization results reveal that plenty of copper ions in composite oxides are incorporated into $\mathrm{CeO}_{2}$ lattice, which produces oxygen vacancies and enhances metal reducibility. Both specific surface area and pore volume of $\operatorname{strCC} x$ samples decreased with the increasing of $\mathrm{Cu}$ loading. The flake-like $\mathrm{CuCeO}_{2-\delta}$ sample $(\mathrm{Cu} /(\mathrm{Cu}+\mathrm{Ce})=0.15)$ with highest specific surface area $\left(108.2 \mathrm{~m}^{2} / \mathrm{g}\right)$ and surface oxygen concentration is indentified as the most active catalyst with propanal totally destructed at $230^{\circ} \mathrm{C}$. The introduction of $\mathrm{H}_{2} \mathrm{O}$ has a negative effect on propanal removal, and the synthesized catalyst has high tolerance to moisture. In conclusion, the specific surface area and surface oxygen density are two vital factors governing the catalytic activity of composite catalysts.
\end{abstract}

(c) 2015 Elsevier Inc. All rights reserved.

\footnotetext{
* Corresponding authors. Fax: +86 2982665110 (C. He), +86 2982668572 (H. Pan).

E-mail addresses: chi_he@mail.xjtu.edu.cn (C. He), panhua@mail.xjtu.edu.cn (H. Pan).
} 


\section{Introduction}

Volatile organic compounds (VOCs) emitted from many industrial processes are considered as great contributors to atmospheric pollution and to be dangerous to human health [1]. Catalytic oxidation offers interesting advantages toward conventional flame combustion or other treatment approaches. It is able to remove dilute VOCs from industrial effluents to very low levels, which may meet the stringent emission requirements in future. Moreover, this technique carries out at low temperature, thereby reducing or even avoiding the use of auxiliary fuel, and inhibiting the formation of toxic byproducts such as dioxin and $\mathrm{NO}_{x}[2]$. Catalytic oxidation of VOCs has been performed either with noble-metal catalysts or with non-noble-metal catalysts, where the noble-metal catalysts generally exhibited better catalytic performances [3], but their applications have been hampered by the high cost of noble metals. Transition metal oxides have much lower cost and higher reaction resistance to thermal and heteroatom poisoning [4], while their limited activity at low temperatures does not make them competitive in comparison with the noble-metal catalysts [5]. Exploiting low cost noble-metal-free catalysts with high activity would be much more desirable.

Different protocols have been reported for the synthesis of transition metal oxide-contained catalysts in previous work, such as sol-gel, incipient impregnation, thermal combustion, one-pot polymeric precursor, co-precipitation, micro-emulsion, and spray pyrolysis, while the surface area and porosity of obtained catalysts were rather low [6-10]. Catalytic reactions always take place on the surface of catalyst and the reaction rates are usually in proportion to the molecule reachable surface area [11] though many other factors also have important effects on catalytic activity. Therefore, porous supports with high surface areas (e.g., $\gamma-\mathrm{Al}_{2} \mathrm{O}_{3}$, zeolite, porous carbon, and molecular sieve) were usually adopted, while the active phase loadings were always strictly controlled to avoid the aggregation of active sites [12-15]. In-situ creating mesoporous structures is a very favorable and feasible option to achieve metal oxides with high surface areas $[16,17]$. In addition, the mesostructure can also improve the diffusion of guest molecules. There are two representative routes to synthesize mesoporous metal oxides, that is, using the supramolecular surfactants as the soft templates and porous materials (e.g., silica or carbon-based materials) as the hard templates $[18,19]$. However, many shortcomings such as complex synthesis procedure, cost and availability of the templates, and treatment of secondary effluents limit the vast applications of above methods.

Among all transition metal oxides, copper loaded catalysts are known to be very active for oxidation reactions [20-22]. The use of metallic oxide promoters that are composed of rare earth elements can lead to an improvement in oxygen storage capability in solids, which evidently enhances the oxidation processes [23]. The most important property of ceria is to serve as an oxygen reservoir that stores and releases oxygen via the redox shift between $\mathrm{Ce}^{4+}$ and $\mathrm{Ce}^{3+}$, which under oxidizing and reducing conditions leads to a high activity of catalysts [24]. $\mathrm{CuCeO}_{x}$ were found to be a kind of very powerful catalysts for oxidation reactions, even comparable to the supported noble-metal catalysts [25] as the introduction of ceria can stabilize the active $\mathrm{Cu}$ sites, affect the $\mathrm{Cu}$ redox property, and improve the oxygen diffusivity and storage capacity of the composite catalysts [26]. Mesoporous $\mathrm{CuO}-\mathrm{CeO}_{2}$ composite catalysts were prepared via soft or hard template approach in previous literature, while the synthesis procedures were either complicated or highly expensive as lots of surfactants were usually required [27,28]. Starch as a polysaccharide bio-template is more attractive for industrial use because of its renewability, biodegradability, simple chemical modification, and low cost. Many porous metal oxides such as $\mathrm{NiO}$ and $\mathrm{ZnO}$ have been synthesized using soluble starch as template, based on the fact that polysaccharides can combine with metal cations in solution because of their coordinating functional groups [29,30]. Moreover, researchers have found that the surface modified starches containing surface carboxyl, amino, or hydrosulfuryl groups possessed much higher chelating capacity for metal ions [31,32], and water-soluble polymers are powerful tools for controlling particle shape, size, and size distribution [33,34].

In the present work, we demonstrate a low cost and effective route for the synthesis of metal composite oxides with mesoporous structure. The evident advantage of this method presents here is the simplicity and effectiveness of the synthesis process, and the abundant and inexpensive of the raw materials, which are very important for large-scale applications. Highly crystalline flake-like mesoporous $\mathrm{CuCeO}_{2-\delta}$ oxides with high surface area and narrow pore size distribution were synthesized. Propanal was adopted as the probe pollutant to evaluate the catalytic efficiency of prepared catalysts, and the catalytic performance of all catalysts is correlated with their physicochemical parameters, namely, surface area, reducibility, oxygen distribution, and catalyst surface state. Moreover, the influences of $\mathrm{H}_{2} \mathrm{O}$ concentration on propanal removal rate and long-term stability of composite catalyst were further studied.

\section{Experimental}

\subsection{Catalyst preparation}

\subsubsection{Synthesis of solid-state citric acid adduct}

All materials and chemicals (maize starch in food grade; copper acetate, cerium acetate, and other routine reagents were analytical grade) were supplied by Sinopharm Chemical Reagent Co., Ltd. without any further purification. The 2-hydroxy-3-chloropropylcitric acid was prepared via reaction with monosodium citrate and epichlorohydrin ( $\left.n_{\text {monosodium citrate }} / n_{\text {epichlorohydrin }}=9 / 10\right)$ under reflux until one phase was formed. After partial cooling to $60^{\circ} \mathrm{C}$, the above mixture was poured into a beaker containing large excess of absolute ethyl alcohol $\left(v_{\text {alcohol }} / v_{\text {mixture }}=8 / 1\right)$ to remove formed glycols and unreacted epichlorohydrin. Finally, the synthesized compound was filtered, and dried at $80^{\circ} \mathrm{C}$ for $10 \mathrm{~h}$ to obtain the solid-state citric acid adduct (SCA).

\subsubsection{Synthesis of carboxyl contained starch chelating agent}

The carboxyl contained starch was prepared according to the dry technique reported by Khalil and Aly [35]. Typically, native maize starch was thoroughly mixed with powdered $\mathrm{NaOH}$ for 5 min using mechanical stirring, and then the SCA was added at room temperature and mixed for another $5 \min \left(n_{\mathrm{starch}}: n_{\mathrm{SCA}}: n_{\mathrm{NaOH}}=11: 8: 1\right)$. Then the mixture was transferred to a stoppered flask and kept in a thermostatic waterbath at $70{ }^{\circ} \mathrm{C}$ for $2 \mathrm{~h}$. After that, the as-synthesized product was poured into ethanol and the $\mathrm{pH}$ was adjusted to 8.0, filtered, and Soxhlet extracted for $12 \mathrm{~h}$ using an ethanol-water mixture $\left(v_{\text {ethanol }}: v_{\text {water }}=4: 1\right)$. Finally, the product was dried at $80^{\circ} \mathrm{C}$ to obtain the starch-2-hydroxypropylcitric acid (str-CA).

\subsubsection{Synthesis of metal ions-chelated starch and composite catalysts}

To introduce metal ions, the prepared str-CA sample was firstly chelated with copper and cerium cations. Briefly, a mix solution $(200 \mathrm{~mL})$ of $\mathrm{Cu}\left(\mathrm{C}_{2} \mathrm{H}_{3} \mathrm{O}_{2}\right)_{2}$ and $\mathrm{Ce}\left(\mathrm{C}_{2} \mathrm{H}_{3} \mathrm{O}_{2}\right)_{3}$ with a total metal ion concentration of $0.1 \mathrm{M}(\mathrm{Cu} /(\mathrm{Cu}+\mathrm{Ce})=0.15,0.3$, and 0.4 , atomic ratios) was treated with the str-CA sample ( $5.0 \mathrm{~g}$ ) added as solid, and the $\mathrm{pH}$ of the mix solution was adjusted to 6.0 as the str-CA chelating agent was highly protonated in a strong acidic medium and could not effectively interact with the metal ions due to the 


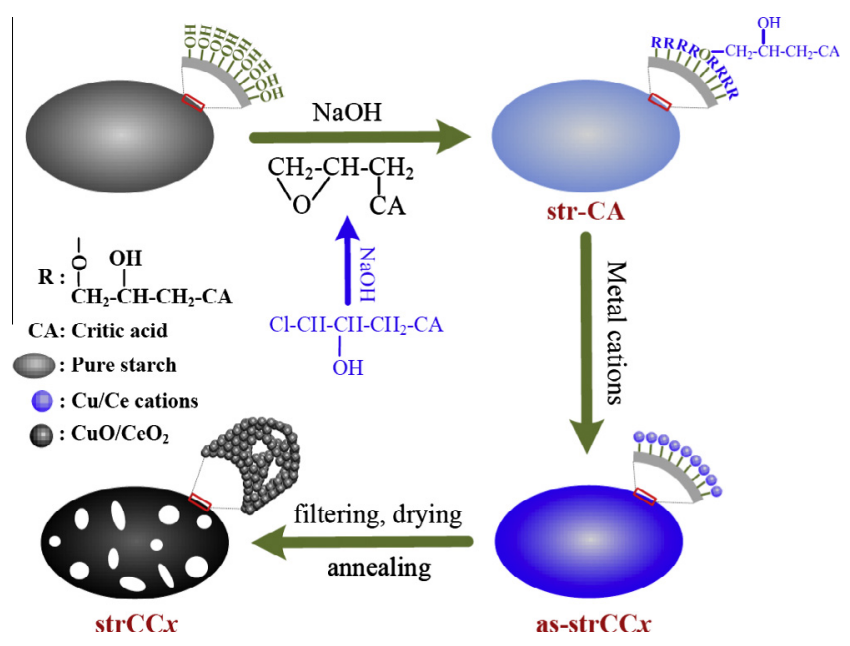

Fig. 1. Schematic synthesis mechanism of the mesostructured $\mathrm{CuCe}_{2-\delta}$ composites.

loss of negative charge [36]. The mixture was then stirred at room temperature for $24 \mathrm{~h}$, washed with distilled water, filtered, and dried at $60^{\circ} \mathrm{C}$ to obtained the metal ions-modified starches (denoted as-strCC $x, x$ is the nominal atomic percent of $\mathrm{Cu}$ in the composite) with different copper contents. Finally, the recovered products were calcined at $550{ }^{\circ} \mathrm{C}$ in air for $4 \mathrm{~h}$ to form the mesoporous composite catalysts (named $\operatorname{strCC} x$ ). For comparison, the $\mathrm{CuCeO}_{2-\delta}$ catalysts with $\mathrm{Cu}$ loading of 30 at.\% were prepared by the coprecipitation (cop), incipient impregnation (imp), and thermal combustion ( $\mathrm{tcb}$ ) methods according to the previous reports $[37,38]$, and the obtained catalysts were respectively denoted as copCC, impCC and tcbCC. Additionally, pure $\mathrm{CuO}$ and $\mathrm{CeO}_{2}$ were also synthesized through thermal calcination their corresponding hydrated metal nitrates at $550^{\circ} \mathrm{C}$ for $4 \mathrm{~h}$.

\subsection{Catalyst characterizations}

X-ray diffraction (XRD) patterns were recorded on a Philips X'Pert powder diffraction system using $\mathrm{Cu} \mathrm{K} \alpha$ radiation $(\lambda=0.15418 \mathrm{~nm})$ in the $2 \theta$ range of $10-80^{\circ}$ (scanning rate of $4^{\circ} \mathrm{min}^{-1}$ ). $\mathrm{N}_{2}$ adsorption/desorption isotherms of catalysts at $-196{ }^{\circ} \mathrm{C}$ were collected on a SSA-4000 gas sorption analyzer. All samples were degassed under vacuum at $300^{\circ} \mathrm{C}$ for $3 \mathrm{~h}$ before the measurement. The total pore volume was estimated from the amount of nitrogen adsorbed at a relative pressure $\left(P / P_{0}\right)$ of 0.99 . The specific surface area was calculated at $P / P_{0}$ of $0.05-0.25$ using the Brunauer-Emmett-Teller (BET) method, and the pore size distribution was derived from the adsorption branch of the $\mathrm{N}_{2}$ isotherm using the Barrett-Joyner-Halenda (BJH) method. Field emission scanning electron microscopy (FE-SEM) images were recorded on a JEOL JSM-6700F microscope. Transmission electron microscopy (TEM) images were collected on a Hitachi H-7650 microscope operating at an acceleration voltage of $80 \mathrm{kV}$. The actual Cu content was determined by inductively coupled plasma optical emission spectroscopy (ICP-OES) on a PerkinElmer OPTIMA 7000 DV. Temperature programmed reduction $\left(\mathrm{H}_{2}-\mathrm{TPR}\right)$ experiments were performed on a Micromeritics ChemiSorb 2720 analyzer. Prior to reduction, $50 \mathrm{mg}$ of the catalyst was heated in a $5 \% \mathrm{O}_{2} / \mathrm{He}$ flow $\left(50 \mathrm{~mL} \mathrm{~min}^{-1}\right)$ from room temperature to $500{ }^{\circ} \mathrm{C}$ and held for $30 \mathrm{~min}$, and then treated in a He stream at room temperature for $30 \mathrm{~min}$ to remove any residual oxygen. The sample was finally reduced under a $5 \% \mathrm{H}_{2} / \mathrm{He}\left(50 \mathrm{~mL} \mathrm{~min}^{-1}\right)$ from 50 to $700{ }^{\circ} \mathrm{C}$ with a heating rate of $10^{\circ} \mathrm{C} \mathrm{min}^{-1}$. Temperature programmed desorption of $\mathrm{O}_{2}\left(\mathrm{O}_{2}\right.$-TPD) was carried out on the same apparatus as that in $\mathrm{H}_{2}$-TPR. $50 \mathrm{mg}$ of the catalyst was pre-heated in a $5 \% \mathrm{O}_{2} / \mathrm{He}$ flow $\left(50 \mathrm{~mL} \mathrm{~min}^{-1}\right)$ at $500{ }^{\circ} \mathrm{C}$ for $30 \mathrm{~min}$, and then the sample was heated from 50 to $700{ }^{\circ} \mathrm{C}$ with a heating rate of $10{ }^{\circ} \mathrm{C} \mathrm{min}-1$ in a pure He stream. X-ray photoelectron spectroscopy (XPS) experiments were carried out on a Kratos AXIS ULTRA instrument under high vacuum $\left(<5 \times 10^{-10}\right.$ torr $)$ using $\mathrm{Al} \mathrm{K} \alpha$ as the exciting radiation at a constant pass energy of $1486.6 \mathrm{eV}$. The $\mathrm{C} 1 \mathrm{~s}$ peak was used to calibrate the binding energy. Diffuse reflectance UV-Vis (DRUV-Vis) spectra were recorded on a Shimadzu UV-3600 spectrophotometer under ambient conditions with the spectral grade $\mathrm{BaSO}_{4}$ as the reference material. Fourier transform infrared spectra (FT-IR) were record using a Bruker Tensor27 IR spectrometer by measuring the absorbance of the $\mathrm{KBr}$ pellet (2 wt.\% sample and $98 \mathrm{wt} . \% \mathrm{KBr}$ ).

\subsection{Catalytic activity}

All evaluation experiments were performed in a continuous-flow fixed-bed reactor at the atmospheric pressure, consisting of a quartz tube ( $4 \mathrm{~mm}$ i.d.) that was filled with the catalyst. The propanal-containing gas was generated by bubbling air through the VOC saturator, and then further diluted with another air stream (propanal concentration $=2500 \mathrm{ppm}$ ) before reaching the reaction bed. Water steam was introduced by delivering the liquid water with a syringe pump (WZ-50C6, Smiths Co., China) into dry air, and the injection point was electrically heated to ensure complete vaporization of the water. Temperatures of catalyst bed and tubular electric furnace were monitored automatically by E-type thermocouples. In each test, $50 \mathrm{mg}$ of catalyst (diluted with 40-60 mesh quartz sand) was placed at the middle of the tube reactor and the total flow rate was kept at $60 \mathrm{~mL} \mathrm{~min}^{-1}$ (gas hourly space velocity (GHSV) of $\mathrm{ca} .36,000 \mathrm{~h}^{-1}$ ). In each test, the catalyst bed temperature was first raised to $100{ }^{\circ} \mathrm{C}$ with the feed stream passing and stabilized for $30 \mathrm{~min}$. Then the temperature was increased to the next point at a heating rate of $5{ }^{\circ} \mathrm{C} \mathrm{min}-1$ and stabilized for $20 \mathrm{~min}$ prior to online analysis of the effluent gas composition in a gas chromatograph (GC9890A, Linghua Co., China) equipped with the flame ionization detector (FID) and thermal conductivity detector (TCD). The conversion of propanal $(X)$ is calculated by Eq. (1), and temperature at which $90 \%$ conversion of propanal are defined as $T_{90}$,

$X=\frac{\left(C_{\text {in }}-C_{\text {out }}\right)}{C_{\text {in }}}$

where $C_{\text {in }}$ and $C_{\text {out }}$ are the propanal concentration in the inlet and outlet streams, respectively.

The reaction rate $(r)$ is calculated with $X$, as Eq. (2),

$r=\frac{F \cdot X}{W_{\mathrm{cat}} \cdot W_{\mathrm{Cu}}}$

where $F$ is the propanal feeding rate $\left(\mathrm{mol} \mathrm{s}^{-1}\right), W_{\text {cat }}$ is the catalyst weight $(\mathrm{g})$, and $W_{\mathrm{Cu}}$ is the copper loading in catalyst.

The effects of reaction products on the reaction rate may be ignored under differential conditions $(X<15 \%)$, and the apparent active energy $\left(E_{a}\right)$ for propanal destruction could be obtained according to Eq. (3),

$r=A \exp \left(\frac{-E_{a}}{R \cdot T}\right) \cdot P_{\text {propanal }}^{\alpha} \cdot P_{\mathrm{O}_{2}}^{\beta}$

where $A$ is the pre-exponential factor, $R$ is the molar gas constant, $T$ is the thermodynamic temperature, and $P_{\text {propanal }}$ and $P_{\mathrm{O}_{2}}$ are the partial pressures of propanal and oxygen, respectively. Parameters of $A, P_{\text {propanal }}{ }^{\alpha}$, and $P_{\mathrm{O}_{2}}^{\beta}$ are nearly constants as the variations of reactant component are negligible under differential reaction conditions. 


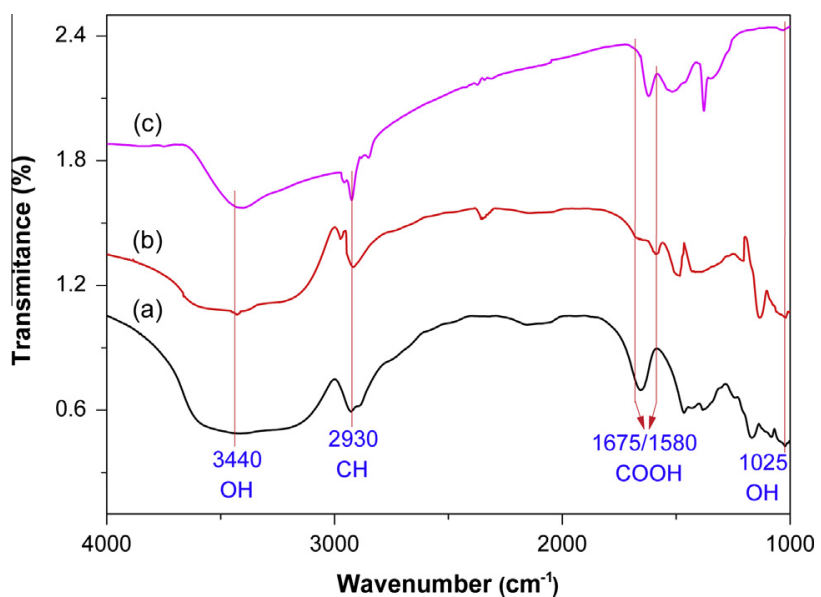

Fig. 2. FT-IR results of (a) native starch, (b) str-CA, and (c) as-strCC15.

The mass transfer limitation was evaluated via the WeiszPrater criterion [39], as Eq. (4),

$\phi_{\mathrm{WP}}=\frac{r_{a} \cdot R_{p}^{2}}{C_{a} \cdot D_{\mathrm{eff}}}$

where $\phi_{\mathrm{WP}}$ is the dimensionless WP parameter, $r_{a}$ is the observed rate per catalyst volume ( $\mathrm{mol} \mathrm{cm} \mathrm{c}^{-3} \mathrm{~s}^{-1}$ ), $R_{p}$ is the radius of the catalyst particle (cm), $C_{a}$ is the gas-phase concentration of propanal at catalyst surface $\left(\mathrm{mol} \mathrm{cm}^{-3}\right)$, and $D_{\text {eff }}$ is the effective diffusivity of propanal $\left(\mathrm{cm}^{2} \mathrm{~s}^{-1}\right)$.

The effective diffusivity of propanal in Eq. (4) can be determined according to Eq. (5),

$D_{\text {eff }}=\frac{1}{3} v d$

where $v$ is the average velocity of propanal molecules in the microreactor $\left(\mathrm{cm} \mathrm{s}^{-1}\right)$, and $d$ is the average pore diameter of catalyst (cm).

\section{Results and discussion}

\subsection{Metal cation chelating and porous composite formation}

The schematic synthesis process of the mesoporous composite catalysts is shown in Fig. 1. Firstly, the maize starch with abundant surface hydroxyl was modified by solid-state citric acid adduct to form str-SCA, and then the carboxyl in str-SCA was ionized under weak acidic solution to form anionic starch intermedium. The ionized carboxyl over starch intermedium can interact with metal cations via electrostatic attraction predominately based on $-\mathrm{COO}^{-} \ldots \mathrm{Cu}^{2+}$ and $-\mathrm{COO}^{-} \ldots \mathrm{Ce}^{3+}$. Finally, the crystallized mesoporous metal composite oxides were obtained after removing the template at $550^{\circ} \mathrm{C}$ as all starch can be removed below $450{ }^{\circ} \mathrm{C}$ (Fig. S1).

Fig. 2 displays the FT-IR spectra of native starch, str-CA, and as-strCC15. Native starch exhibits a broadly stretched intense peak at $3440 \mathrm{~cm}^{-1}$, which is the characteristic adsorption of $\mathrm{O}-\mathrm{H}$. The weak peak at $1025 \mathrm{~cm}^{-1}$ is produced by the stretching vibration of secondary alcohol, and the one observed at $2930 \mathrm{~cm}^{-1}$ is due to the $\mathrm{C}-\mathrm{H}$ stretching vibration [40]. Two IR peaks centered at $1675 \mathrm{~cm}^{-1}$ and $1580 \mathrm{~cm}^{-1}$ assigned to the stretching vibrations of the carboxyl can be found over str-CA, indicating that the 2-hydroxy-3-propylcitric acid group was successfully introduced to the native starch. After metal chelating reaction, the above peaks according to the carboxyl groups were disappeared. In addition, intensities of the $\mathrm{O}-\mathrm{H}$ vibration peaks over as-strCC15 were

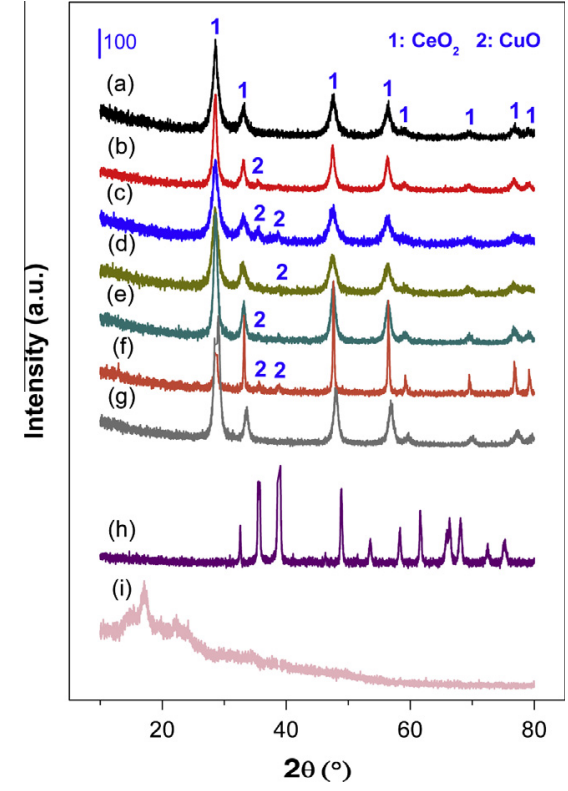

Fig. 3. XRD patterns of (a) strCC15, (b) $\operatorname{strCC} 30$, (c) $\operatorname{strCC} 40$, (d) copCC, (e) impCC, (f) tcbCC, (g) $\mathrm{CeO}_{2}$, (h) $\mathrm{CuO}$, and (i) native starch.

Table 1

Physicochemical properties of synthesized catalysts.

\begin{tabular}{llllll}
\hline Sample & $\begin{array}{l}\mathrm{CeO}_{2} \\
\text { crystallite } \\
\text { size }(\mathrm{nm})\end{array}$ & $\begin{array}{l}\text { Lattice } \\
\text { microstrain } \\
\left(\times 10^{-3}\right)\end{array}$ & $\begin{array}{l}\text { Surface } \\
\text { area } \\
\left(\mathrm{m}^{2} \mathrm{~g}^{-1}\right)\end{array}$ & $\begin{array}{l}\text { Pore } \\
\text { volume } \\
\left(\mathrm{cm}^{3} \mathrm{~g}^{-1}\right)\end{array}$ & $\begin{array}{l}\text { Pore } \\
\text { diameter } \\
(\mathrm{nm})\end{array}$ \\
\hline strCC15 & 14.5 & 9.1 & 108.2 & 0.21 & 4.1 \\
$\mathrm{strCC} 30$ & 17.8 & 9.9 & 92.6 & 0.18 & 4.4 \\
$\mathrm{strCC} 40$ & 16.4 & 12.3 & 84.3 & 0.13 & 3.8 \\
$\mathrm{copCC}$ & 10.0 & 14.1 & 86.5 & 0.14 & 3.2 \\
$\mathrm{impCC}$ & 15.7 & 8.8 & 59.1 & 0.16 & 5.5 \\
$\mathrm{tcbCC}$ & 64.1 & 2.2 & 3.9 & 0.01 & 5.2 \\
$\mathrm{CeO} 2$ & 16 & 8.7 & 60.8 & 0.18 & 6.1 \\
$\mathrm{CuO}$ & $/$ & 1 & $<1.0$ & $/$ & 5.3 \\
\hline
\end{tabular}

Table 2

Characteristic data of synthesized catalysts.

\begin{tabular}{|c|c|c|c|c|c|c|c|c|c|}
\hline \multirow[t]{2}{*}{ Sample } & \multicolumn{2}{|c|}{$\begin{array}{l}\text { Cu content } \\
(\%)\end{array}$} & \multirow[t]{2}{*}{$\begin{array}{l}\mathrm{Cu} \\
(\%)\end{array}$} & \multirow[t]{2}{*}{$\begin{array}{l}\mathrm{Ce} \\
(\%)\end{array}$} & \multirow[t]{2}{*}{$\begin{array}{l}\mathrm{O} \\
(\%)\end{array}$} & \multirow[t]{2}{*}{$\begin{array}{l}\mathrm{Ce}^{3+} \\
(\%)\end{array}$} & \multicolumn{3}{|c|}{$\begin{array}{l}\text { Oxygen } \\
\text { distribution (\%) }\end{array}$} \\
\hline & XPS & $\begin{array}{l}\text { ICP- } \\
\text { OES }\end{array}$ & & & & & $\mathrm{O}_{\text {latt }}$ & $\mathrm{O}_{\text {surf }}$ & $\mathrm{O}_{\mathrm{ads}}$ \\
\hline strCC15 & 12.8 & 12.1 & 6.0 & 25.9 & 68.1 & 34.2 & 56.9 & 41.9 & 1.2 \\
\hline strCC30 & 27.2 & 24.5 & 7.9 & 26.2 & 65.9 & 32.1 & 60.7 & 38.5 & 0.8 \\
\hline strCC40 & 37.5 & 30.7 & 8.8 & 24.4 & 66.8 & 28.0 & 62.9 & 35.9 & 1.2 \\
\hline сорСC & 32.2 & 31.1 & 8.0 & 16.8 & 75.2 & 33.5 & 58.3 & 35.4 & 6.3 \\
\hline impcc & 37.1 & 29.3 & 6.4 & 18.1 & 75.6 & 31.3 & 64.3 & 31.5 & 4.2 \\
\hline tcbCc & 42.6 & 30.5 & 15.6 & 21.0 & 63.4 & 23.3 & 67.8 & 25.3 & 6.9 \\
\hline
\end{tabular}

weaker that those over str-CA and native starch, which suggests that parts of hydroxyl also combined with metal cations by hostguest interactions such as hydrogen bonding, Coulombic interaction, and van der Waals interaction [41].

\subsection{Crystal structure and textural property}

XRD patterns of all catalysts are shown in Fig. 3. Typical cubic fluorite-type structure of $\mathrm{CeO}_{2}$ can be observed in all composite samples (JCPDS No. 81-0792). No diffraction peak of CuO (JCPDS No. 80-1268) can be found over strCC15, indicating the fine 

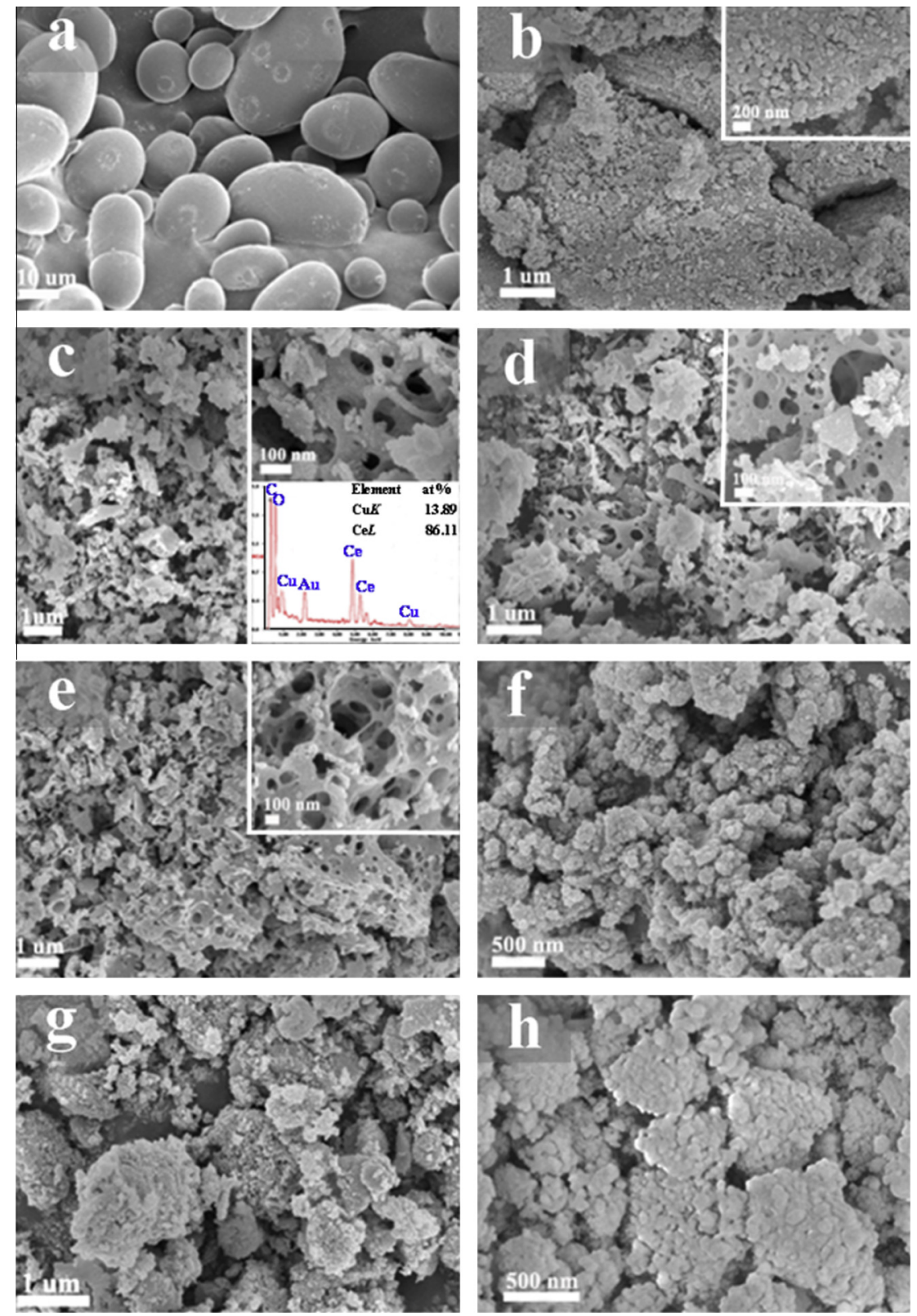

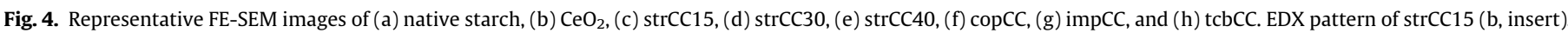

dispersion of $\mathrm{CuO}$ particles or the incorporation of copper phase into ceria lattice $[28,42]$. However, CuO diffraction peaks at $35.2^{\circ}$ or/and $38.3^{\circ}$ can be observed over the other composite catalysts, which suggests the partial aggregation of $\mathrm{CuO}$ particles. Furthermore, the $\mathrm{Cu}$ phase aggregation degree over tcbCC and strCC40 is higher than that over strCC30, copCC, and impCC. Meanwhile, the increase of lattice microstrain (calculated from the (111) reflection of $\mathrm{CeO}_{2}$ using the Williamson-Hall plot method [13]) of composite samples also approves the incorporation of $\mathrm{Cu}$ phase, as listed in Table 1. Bulk Cu contents of composite catalysts are characterized by ICP-OES, as illustrated in Table 2. The actual $\mathrm{Cu}$ contents of copCC, impCC, and tcbCC are approximately equal to the theoretical $\mathrm{Cu}$ loadings. While the bulk $\mathrm{Cu}$ contents in all anionic starch induced composites are obviously lower than the theoretical values, suggesting that $\mathrm{Ce}^{3+}$ cation with more positive charge is easier to be chelated by the ionized carboxyl than that of $\mathrm{Cu}^{2+}$. The surface composition of synthesized catalysts is further estimated by XPS, and the results reveal that $\mathrm{Cu}$ species are uniform distributed in strCC15 and copCC from surface to interior, while the enrichment of $\mathrm{Cu}$ species can be found over tcbCC and strCC40 (Table 2), in consistence with the XRD result (Fig. 3).

As can be seen in Fig. S2, copCC, impCC, and $\mathrm{CeO}_{2}$ possess well expressed H1-type hysteresis loops at relative pressure of 0.8-1.0, corresponding to the presence of textural pores contributed to the filling of interparticle spaces [43]. All $\operatorname{strCC} x$ samples show typical IV shape isotherms with distinct H1-type hysteresis loops observed in the range of $0.45-1.0$, indicating the coexistence of structural $\left(P / P_{0}=0.45-0.8\right)$ and interparticle accumulation mesopores [27]. The pore diameter distribution curves of $\operatorname{strCC} x$ show one single peak at $4.0 \mathrm{~nm}$ (much narrower than those of copCC, impCC, and $\mathrm{CeO}_{2}$ ), suggesting the good homogeneity of the mesopores. The BET surface areas of $\operatorname{strCC} x$ samples are measured to be $84.3-108.2 \mathrm{~m}^{2} \mathrm{~g}^{-1}$, obviously larger than those of $\mathrm{CuO}\left(<1.0 \mathrm{~m}^{2} \mathrm{~g}^{-1}\right)$ and $\mathrm{CeO}_{2}\left(60.8 \mathrm{~m}^{2} \mathrm{~g}^{-1}\right)$. In addition, the decrease 
of BET surface area and pore volume of $\operatorname{strCC} x$ composites can be noticed with the increasing of $\mathrm{Cu}$ content (Table 1 ).

Fig. 4a reveals that the native maize starch possesses sphere-like and spheroid-like granular structure in the size range of $8-30 \mu \mathrm{m}$, and $\mathrm{CeO}_{2}$ nanoparticles with average diameter of $c a$. $30 \mathrm{~nm}$ can be observed in Fig. 5b. Morphology of $\operatorname{strCC} x$ are much different from those of the native starch and samples synthesized via the imp, cop, and tcb approaches (Fig. 4a, c-h). The strCC $x$ composites have shaggy and flake-like micromorphologies with plenty of pores over their walls, and this porous structure with short pore channels should possesses unique advantages in mass and heat transfer during oxidation reactions [44]. EDX result indicates that Cu content over strCC15 (13.89 at.\%) is a little lower than the nominal value (Fig. 4c, insert), in agreement with the XPS and ICP-OES results (Table 2 ). In addition, a portion of particles over impCC and copCC aggregate to some degree, while these particles are badly aggregated over tcbCC (Fig. 4f and g). Microstructure of prepared composite catalysts is further studied by TEM (Fig. S3). Nanoparticles with diameter of $10-20 \mathrm{~nm}$ are well dispersed and lots of structural or interparticle accumulation mesopores can be found over strCC15. However, particles over strCC30 and strCC40 seems to agglomerate to some extent, especially for strCC40 sample (Fig. S3a-c). The copCC sample also presents a well dispersed morphology, while the metal particles are prone to aggregated to clusters over impCC (ca. $40 \mathrm{~nm}$ ) and tcbCC (ca. $200 \mathrm{~nm}$ ) (Fig. S3d-f), in consistent with the SEM result in Fig. 4.

\subsection{Reducibility and oxygen mobility}

Reducibility of synthesized catalysts were studied by $\mathrm{H}_{2}$-TPR (Fig. 5A). All composite samples have much better reducibility than that of $\mathrm{CuO}$ and $\mathrm{CeO}_{2}$ due to the synergy effect between $\mathrm{Cu}$ and $\mathrm{Ce}$ components as the $\mathrm{Cu}^{x+}-\mathrm{O}^{2-}-\mathrm{Ce}^{y+}$ connection could reduce the redox potential of metal species. Similar reduction behaviors can be noticed for $\operatorname{strCC} x$ samples with three reduction peaks below $320^{\circ} \mathrm{C}$, and the reducibility of $\operatorname{strCC} x$ composites is continuously decreased when increases the $\mathrm{Cu}$ contents probably due to the reduction of $\mathrm{H}_{2}$ accessible surface areas [27] or the aggregation of $\mathrm{Cu}$ species (Table 1 and Fig. 3). The first two $\mathrm{H}_{2}$ consumption peaks $\left(<200^{\circ} \mathrm{C}\right)$ over $\operatorname{strCC} x$ samples can be respectively assigned to the reduction of well-dispersed $\mathrm{CuO}$ and framework $\mathrm{CuO}$ in $\mathrm{CeO}_{2}$ lattice, while the $\mathrm{H}_{2}$ consumptions higher than $200{ }^{\circ} \mathrm{C}$ over strCC30 and strCC40 are attributed to the reduction of $\mathrm{CuO}$ cluster [2]. The copCC sample with a large portion of $\mathrm{Cu}$ species reduced at $169^{\circ} \mathrm{C}$ shows much better reducibility than that of impCC and tcbCC due to better dispersion of $\mathrm{Cu}$ species. The $\mathrm{H}_{2}$ consumption amounts below $300{ }^{\circ} \mathrm{C}$ over all composite catalysts are shown in Table S1. Overall considering the reduction temperature and low-temperature $\mathrm{H}_{2}$ consumption amount, the reducibility of synthesized catalysts is in the order of $\operatorname{copCC}>\operatorname{strCC} 15>$ strCC30 $>$ impCC $>$ strCC $40>\operatorname{tcbCC}>\mathrm{CeO}_{2}>\mathrm{CuO}$.

As shown in Fig. 5B, the desorption of physically adsorbed oxygen $\left(\mathrm{O}_{2}\right)$ is not detected over all samples. The $\operatorname{strCC} x$ and $\operatorname{copCC}$ catalysts exhibit three oxygen desorption peaks, while impCC and tcbCC samples just present two oxygen desorption peaks centered at higher temperature range of $370-640^{\circ} \mathrm{C}$. Three desorption peaks below $460{ }^{\circ} \mathrm{C}$ over $\operatorname{strCC} x$ and copCC samples could be assigned to the chemically adsorbed oxygen $\left(\mathrm{O}_{2}^{-} / \mathrm{O}^{-}\right.$, ad) atom as the quick desorption of the oxygen species, and the unsymmetric desorption peaks higher than $570{ }^{\circ} \mathrm{C}$ over composite catalysts can be assigned to the lattice $\mathrm{O}^{2-}$ species [38]. It is worth noting that the a large number of catalytically active $\mathrm{O}_{2}^{-}$or $\mathrm{O}^{-}$species can desorb from $\operatorname{strCC} x$ catalysts at very low temperatures $\left(<180^{\circ} \mathrm{C}\right)$. Furthermore, $\operatorname{strCC} x$ has larger quantity of $\mathrm{O}_{2}^{-}$or $\mathrm{O}^{-}$species than the other samples, and the concentration of $\mathrm{O}_{2}^{-}$or $\mathrm{O}^{-}$species is in the sequence of $\operatorname{strCC} 15>\operatorname{strCC} 30>\operatorname{strCC} 40>\operatorname{copCC}>\operatorname{tcbCC} \approx$ impCC $>$
$\mathrm{CeO}_{2}>\mathrm{CuO}$ according to the deconvolution peak areas under TPD curves.

\subsection{Surface state and structural property}

The surface state and composition of synthesized catalysts were investigated by XPS, as shown in Fig. 6 and Table 2. As is known, the presence of $\mathrm{Ce}^{3+}$ in $\mathrm{CeO}_{2}$ means the formation of oxygen vacancy, which could accelerate oxygen transfer rate during oxidation reaction. Results in Fig. $6 \mathrm{~A}$ and Table 2 reveal that the percentage of $\mathrm{Ce}^{3+}$ in $\operatorname{strCC} x$ decreases to some degree with the increasing of $\mathrm{Cu}$ contents according to the fitted peak areas underlying the original XPS curves $\left(\mathrm{Ce}^{3+}=u^{\prime}+u_{0}+v^{\prime}+v_{0}\right)$, and the $\mathrm{Ce}^{3+}$ contents in all composite catalysts are following the sequence of $\operatorname{strCC} 15(34.2 \%)>\operatorname{copCC}(33.5 \%)>\operatorname{strCC} 30 \quad(32.1 \%)>$ impCC $(31.3 \%)>\operatorname{strCC} 40(28.0 \%)>\operatorname{tcbCC}(23.3 \%)$. The Cu state was studied by $\mathrm{Cu} 2 \mathrm{p}$ and $\mathrm{Cu}$ LMM Auger lines, as demonstrated in Fig. $6 \mathrm{~B}$ and $\mathrm{C}$. Two peaks centered at 934.3 and $932.5 \mathrm{eV}$ can be reasonably attributed to the existence of $\mathrm{Cu}^{2+}$ and reduced $\mathrm{Cu}$ species (i.e., $\mathrm{Cu}^{1+}$ and/or $\mathrm{Cu}^{0}$ ), respectively [2]. Cu LMM Auger lines were further studied in order to clarify the composition of the reduced Cu species (Fig. 6C), and the peaks at 917.1 and $912.9 \mathrm{eV}$ respectively correspond to the $\mathrm{Cu}^{2+}$ and $\mathrm{Cu}^{1+}$ [45]. The distribution of oxygen species was also investigated, as shown in Fig. 6D. XPS curves can be decomposed to three peaks with binding energies centered at 529.1, 531.4, and 532.4 eV, corresponding to the lattice oxygen $\left(\mathrm{O}_{\text {latt }}\right)$, surface oxygen $\left(\mathrm{O}_{\text {surf }}\right)$, and adsorbed oxygen $\left(\mathrm{O}_{\text {ads }}\right)$, respectively [9]. The $O 1 \mathrm{~s}$ core level of $\mathrm{O}_{\text {latt }}$ over all composite samples shifts to higher values due to " $\mathrm{O} \rightarrow \mathrm{Cu}$ " electron-transfer processes, which can create active oxygen species such as $\mathrm{O}, \mathrm{O}_{2}^{-}, \mathrm{O}^{-}$, and $\mathrm{O}^{2-}[2]$. The oxygen species distribution over different
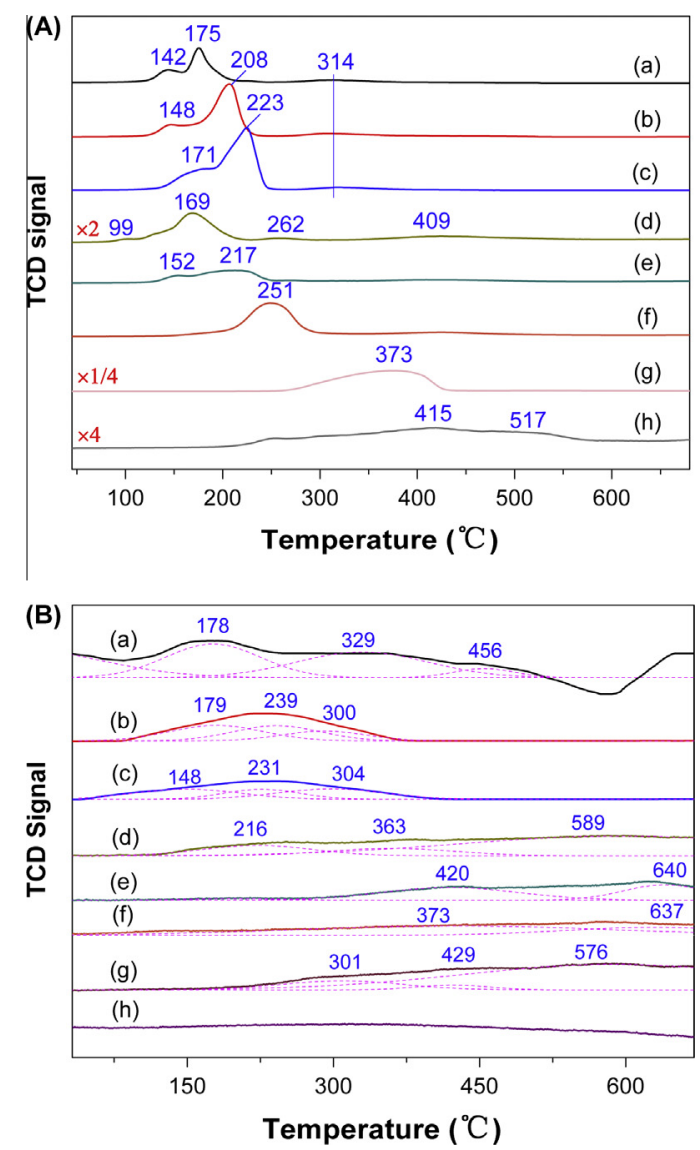

Fig. 5. (A) $\mathrm{H}_{2}$-TPR and (B) $\mathrm{O}_{2}$-TPD profiles of (a) $\operatorname{strCC} 15$, (b) $\operatorname{strCC} 30$, (c) $\operatorname{strCC} 40$, (d) copCC, (e) impCC, (f) tcbCC, (g) $\mathrm{CeO}_{2}$, and (h) CuO. 

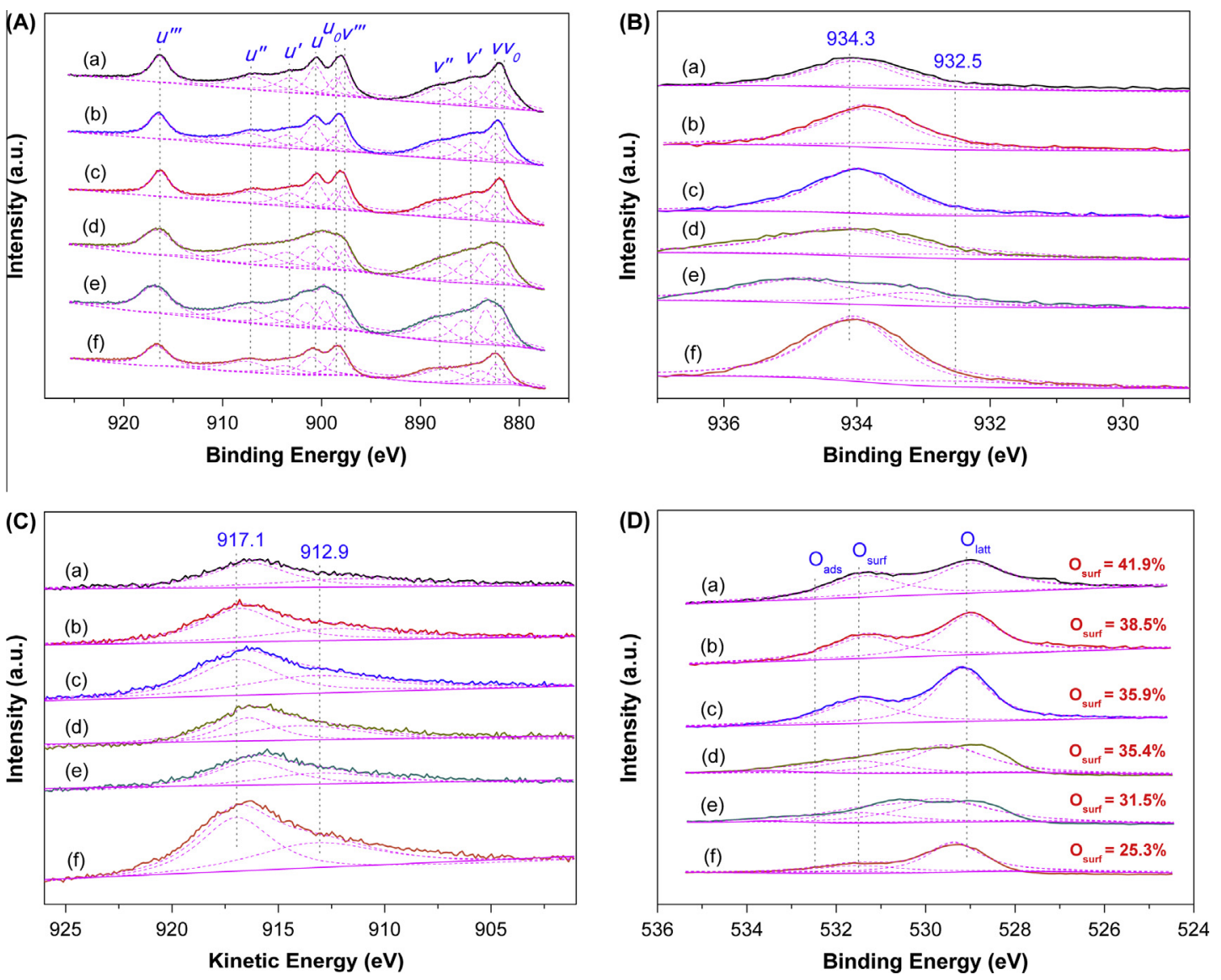

Fig. 6. (A) Ce 3d, (B) Cu 2p, (C) Cu LMM, and (D) O1s spectra of (a) strCC15, (b) strCC30, (c) strCC40, (d) copCC, (e) impCC, and (f) tcbCC.

catalysts is listed in Table 2 . As can be observed, the concentration of $\mathrm{O}_{\text {surf }}$ in $\operatorname{strCC} x$ catalysts is more or less higher than that of the other samples synthesized via the cop, imp, and tcb approaches. The percentage of $\mathrm{O}_{\text {surf }}$ in all composites is in the order of $\operatorname{strCC} 15 \quad(41.9 \%)>\operatorname{strCC} 30 \quad(38.5 \%)>\operatorname{strCC} 40 \quad(35.9 \%) \approx \operatorname{copCC}$ $(35.4 \%)>\operatorname{impCC}(31.5 \%)>\operatorname{tcbCC}(25.3 \%)$.

Structural characters of the synthesized metal composites were explored by DRUV-Vis (Fig. S4). Adsorption peaks at 228, 279, and $346 \mathrm{~nm}$ over $\mathrm{CeO}_{2}$ can be respectively attributed to the $\mathrm{f} \rightarrow \mathrm{d}$ transition of $\mathrm{Ce}^{3+}$, the low coordinated $\mathrm{Ce}^{4+}-\mathrm{O}$ charge transfer, and the interband transition [28]. Absorption peak at $448 \mathrm{~nm}$ is assigned to the emission and absorption of one photo by $\mathrm{Cu}^{1+}$ complexes, which suggests the presence of reduced copper species. Moreover, the adsorption peak decreases from 673 to $649 \mathrm{~nm}$ when the $\mathrm{Cu}$ contents increase from 15 to 40 at.\%, indicating that most of copper species in strCC15 is in the form of pyramidal or tetrahedral copper complexes, while a large number of octahedral $\mathrm{O}_{\mathrm{h}}$ configurated copper presents in strCC40 [46]. Oxidation state and local structure of $\mathrm{Cu}$ species over strCC15 were further investigated by copper K-edge XANES (Fig. S5). The small transition adsorption at $8.981 \mathrm{keV}$ indicates the existence of reduced $\mathrm{Cu}^{1+}$, in agreement with the $\mathrm{Cu}$ LMM and DRUV-Vis results (Figs. 6C and S4). The absence of edge transition peak between 8.982 and $8.987 \mathrm{keV}$, and the stronger line intensity at $8.992-9.007 \mathrm{keV}$ is due to the interaction of $\mathrm{Cu}$ and Ce species [47]. Besides, the $\mathrm{k}^{3}$ -weighted Fourier transform magnitudes of the EXAFS curve proves the presence of $\mathrm{Cu}^{2+}$ (Fig. S5, insert).

\subsection{Catalytic activity and long-term stability}

Fig. 7A shows the catalytic activity of prepared catalysts for propanal destruction. Propanal conversion cannot be observed below
$350{ }^{\circ} \mathrm{C}$ during the blank test. Only $\mathrm{CO}_{2}, \mathrm{H}_{2} \mathrm{O}$ and a tiny amount of $\mathrm{CO}$ can be detected in the effluent during catalytic tests (carbon balance $>99.5 \%$ ). Based on the Weisz-Prater criterion [39], when the effectiveness factor $\eta \geqslant 0.95$ and reaction order $n=1$, the $\phi_{\mathrm{WP}}$ value is less than 0.3 , which can be considered as a sufficient condition for the absence of significant pore diffusion limitations. Herein the Weisz-Prater analysis was carried out at low propanal conversion $(X<15 \%)$, and the $\phi_{\mathrm{WP}}$ values $\left(\mathrm{ca} .1 .17 \times 10^{-2}\right)$ are remarkably lower than 0.3 . Thus, no significant mass transfer limitations exist in the present work. StrCC $x$ and copCC catalysts have excellent activity with $100 \%$ propanal destructed below $300{ }^{\circ} \mathrm{C}$, and the activity of $\operatorname{strCC} x$ decreases obviously when increase the $\mathrm{Cu}$ species loadings. Among them, strCC15 possesses the highest activity with propanal totally destructed at $230^{\circ} \mathrm{C}$, and this temperature is much lower than the other catalysts. The activity sequence of all catalysts is $\operatorname{strCC} 15>\operatorname{strCC} 30>\operatorname{copCC}>\operatorname{strCC} 40>$ impCC $>$ tcbCC $>\mathrm{CuO}>\mathrm{CeO}_{2}$ (Fig. 7A and Table 3). Furthermore, the reaction rate and apparent activation energy were calculated based on the slopes of Arrhenius plots (Fig. 7B and Table 3). The propanal oxidation rate over strCC15 is significantly higher than the other catalysts. For example, the reaction rate of strCC15 at $225^{\circ} \mathrm{C}$ can reach up to $3.99 \mathrm{mmol} \mathrm{g}^{-1} \mathrm{~h}^{-1}$, which is $1.4,3.4$, and 19.9 times higher than copCC $\left(2.84 \mathrm{mmol} \mathrm{g}^{-1} \mathrm{~h}^{-1}\right)$, impCC $\left(1.15 \mathrm{mmol} \mathrm{g}^{-1} \mathrm{~h}^{-1}\right)$, and tcbCC $\left(0.20 \mathrm{mmol} \mathrm{g}^{-1} \mathrm{~h}^{-1}\right)$, respectively. Moreover, the $\operatorname{strCC} x$ has lower apparent activation energy values (97.1-121.3 $\mathrm{kJ} \mathrm{mol}^{-1}$ ) than those of the other samples (130.5$511.5 \mathrm{~kJ} \mathrm{~mol}^{-1}$ ), which further demonstrate the superior destruction activity of $\operatorname{strCC} x$ catalysts, especially the strCC15 sample $\left(97.1 \mathrm{~kJ} \mathrm{~mol}^{-1}\right)$.

Most of industrial processes produce flue gases containing different amounts of water vapor, thus the effect of water vapor on propanal destruction process needs carefully investigation. 

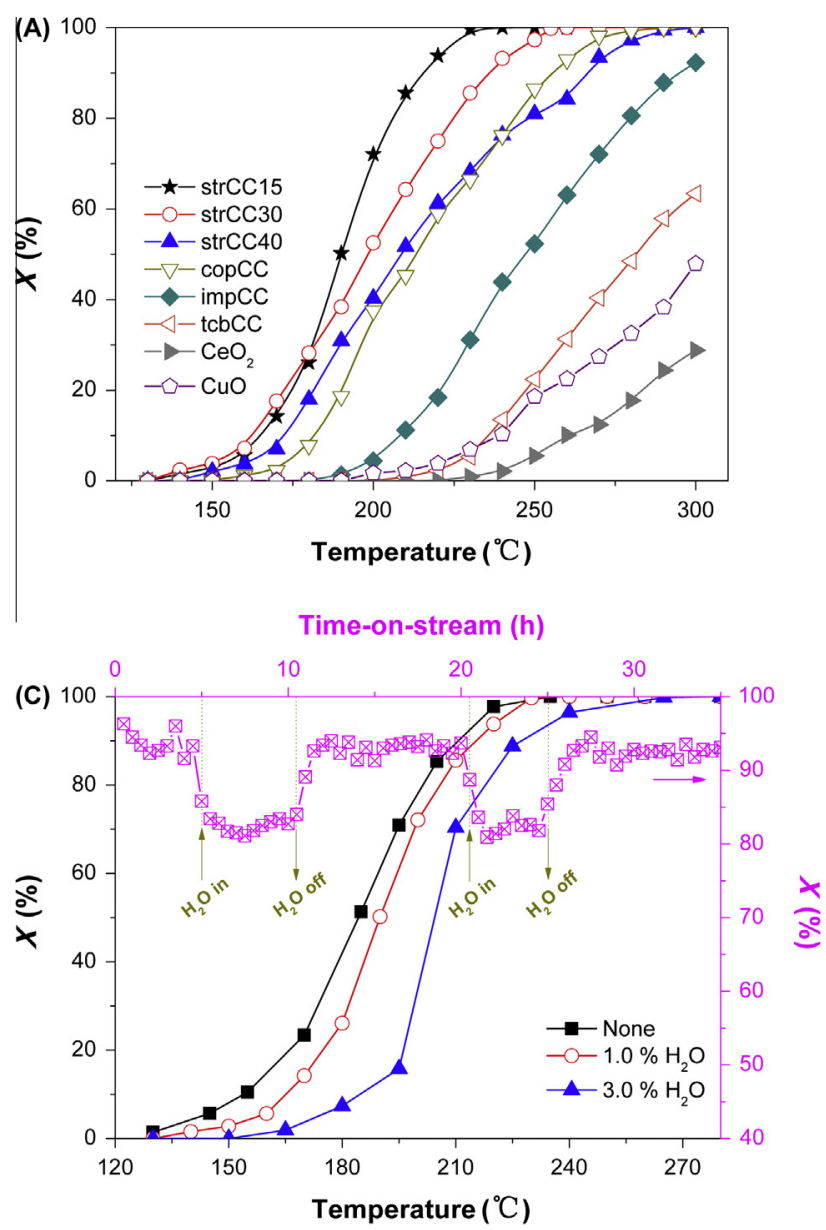
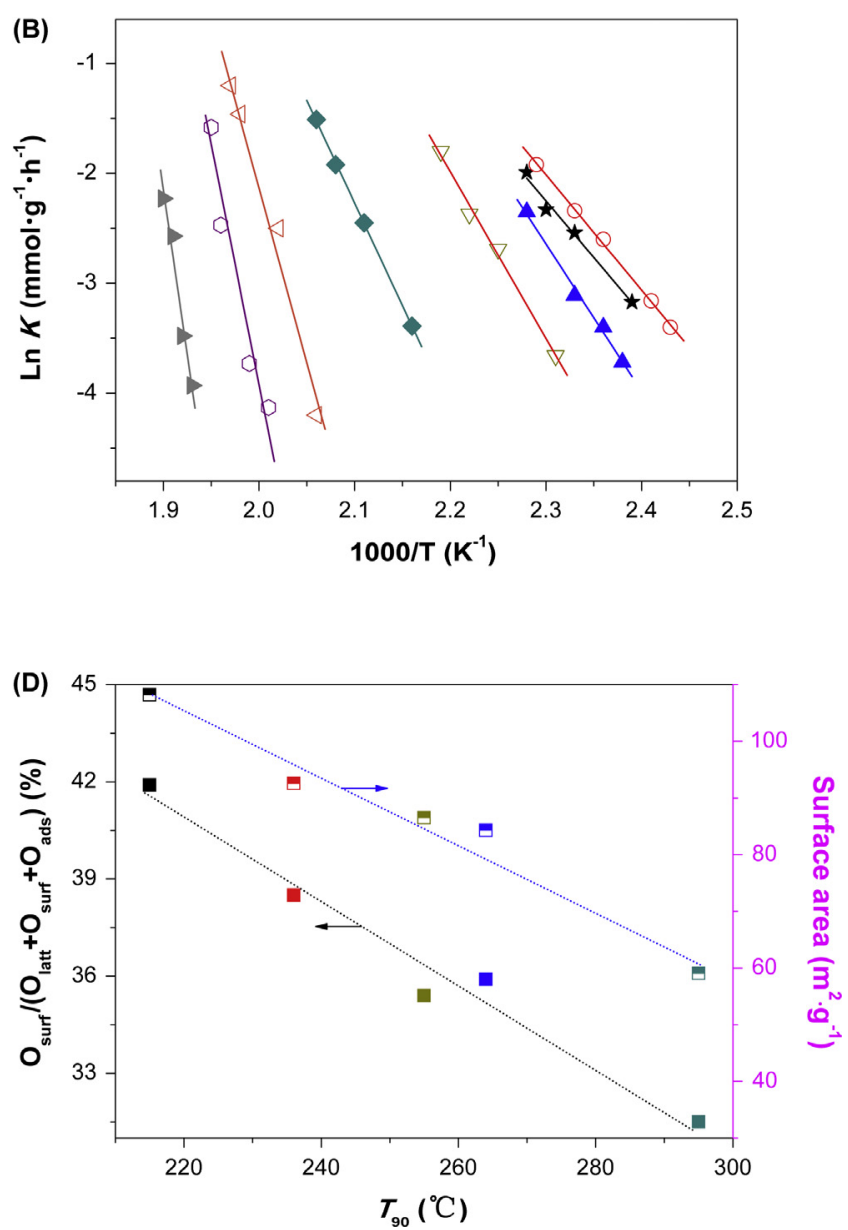

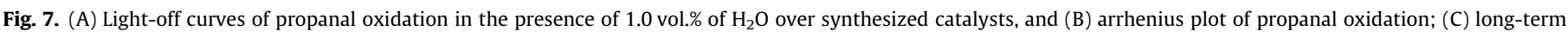

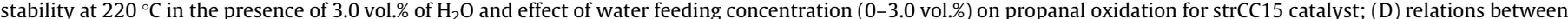
$T_{90}$ and surface oxygen concentration and specific surface area.

Furthermore, the catalyst stability in dry or humid conditions is always a most important parameter for practical applications. Fig. 7C displays the oxidation behaviors of propanal over most active strCC15 catalyst in the presence of different water vapor concentrations. The water vapor has a negative effect on propanal removal, and the $T_{90}$ temperatures increase $17{ }^{\circ} \mathrm{C}$ when 3.0 vol.\% of water vapor is added to the system. Besides, the inhibition effect of $\mathrm{H}_{2} \mathrm{O}$ molecules on $\mathrm{CuCeO}_{2-\delta}$ catalyst in this work seems much weak than that on Al-containing materials probably due to the hydrophobicity of metal composite [48]. The long-term durability of strCC15 catalyst at $220^{\circ} \mathrm{C}$ in dry and humid conditions was studied by stepwise addition and removal of water vapor (3.0 vol.\%). The result in Fig. 7C reveals that the catalytic activity of strCC15 is inhibited by the water molecules as propanal conversion drops instantaneously when 3.0 vol.\% of $\mathrm{H}_{2} \mathrm{O}$ is introduced. Noticeably, after switching back to the water-free reaction conditions, the propanal conversion increases immediately and return to the initial value gradually, and this indicates that the synthesized catalyst has a high tolerance to moisture.

The XRD, XPS and copper K-edge XANES results reveal that a large amount of copper species migrated into $\mathrm{CeO}_{2}$ lattice of the strCC $x$ samples in the form of the $\mathrm{Cu}_{x} \mathrm{Ce}_{1-x} \mathrm{O}_{2-\delta}$ solid solution (Figs. 3 and 6, and S5). The $\mathrm{Cu}^{x+}-\mathrm{O}^{2-}-\mathrm{Ce}^{y+}$ connection in the solid solution can reduce the redox potential of copper species as well as act as a bridge for $\mathrm{O}$ transfer between $\mathrm{Cu}$ and $\mathrm{Ce}$ phases. Thus, the interaction between $\mathrm{Cu}$ and $\mathrm{Ce}$ in the solid solution ensures that the reducibility is enhanced for both compounds, and this allows an effective redox cycle (i.e., $\mathrm{Cu}^{2+} / \mathrm{Cu}^{1+} \underset{\mathrm{O}_{2}^{-} / \mathrm{O}^{-}}{\stackrel{2 \mathrm{e}^{-}}{\leftrightarrows}} \mathrm{Ce}^{4+} / \mathrm{Ce}^{3+}$ ) to occur during oxidation reactions. Researchers proposed that the activation of propane and propene over $\mathrm{MnO}_{x}$ and $\mathrm{MnO}_{x^{-}}$ $\mathrm{CeO}_{2}$ metal oxides is thought to occur by abstraction of the $\mathrm{H}$ atoms from the weakest $\mathrm{C}-\mathrm{H}$ bonds, with a simultaneous reduction of the surface sites and successive formation of the surface hydroxide ions $[49,50]$. In the present work, it is inferred that the active oxygen can also preferentially extract the $\mathrm{H}$ atoms from the weakest $\mathrm{C}-\mathrm{H}$ bonds in propanal molecules, and more active oxygen species should favor the activation of propanal. It is generally accepted that the specific surface area, active oxygen availability, and reducibility of a transition metal oxide are most important factors deciding its catalytic activity [51,52]. The oxidation reactions of organic compounds over the transition metal oxide catalysts are known to occur through two possible mechanisms, that is, the suprafacial and/or intrafacial mechanism [53]. The former mechanism is operative at reaction temperature $(T)<400^{\circ} \mathrm{C}$ and involves oxygen species adsorbed over the surface oxygen vacancies of the catalyst. The latter one takes place at $T>400^{\circ} \mathrm{C}$ and involves the lattice oxygen of the catalyst through a Mars-van Krevelen redox cycle $[54,55]$. In the latter case, a direct relation between the catalyst reducibility and the activity takes place [56]. Herein, the presence of oxygen vacancies due to the incorporation of copper species facilitate the activation of oxygen molecules to active oxygen adspecies, and reducibility of the synthesized composite catalysts is obviously improved (especially for the sample with large specific surface area) comparing with bulk $\mathrm{CuO}$ and $\mathrm{CeO}_{2}$ oxides due to the $\mathrm{Cu}^{x+}-\mathrm{O}^{2-}-\mathrm{Ce}^{y+}$ connection in $\mathrm{Cu}_{x} \mathrm{Ce}_{1-x} \mathrm{O}_{2-\delta}$ solid solution. The reducibility sequence of 
Table 3

Catalytic performance of the synthesized catalysts.

\begin{tabular}{lllll}
\hline Sample & $\begin{array}{l}T_{90}{ }^{\mathrm{a}} \\
\left({ }^{\circ} \mathrm{C}\right)\end{array}$ & $\begin{array}{l}\text { Reaction rate } \\
\left(\mathrm{mmol} \mathrm{g}^{-1} \mathrm{~h}^{-1}\right)\end{array}$ & $\begin{array}{l}\text { Activation energy } \\
\left(\mathrm{kJ} \mathrm{mol}^{-1}\right)\end{array}$ & $R^{2}$ \\
\hline strCC15 & 215 & 3.99 & 97.1 & 0.978 \\
strCC30 & 236 & 3.31 & 101.8 & 0.998 \\
strCC40 & 264 & 2.56 & 121.3 & 0.992 \\
copCC & 255 & 2.84 & 130.5 & 0.966 \\
impCC & 295 & 1.15 & 159.1 & 0.996 \\
tcbCC & $/$ & 0.20 & 278.2 & 0.964 \\
$\mathrm{CeO}_{2}$ & $/$ & 0.01 & 511.5 & 0.968 \\
$\mathrm{CuO}^{\mathrm{i}}$ & $/$ & 0.23 & 372.4 & 0.962 \\
\hline
\end{tabular}

a Temperature at which $90 \%$ conversion of propanal.

b Propanal reaction rate gained at $225^{\circ} \mathrm{C}$.

synthesized catalysts (copCC $>\operatorname{strCC} 15>\operatorname{strCC} 30>$ impCC $>$ strCC40 $>\operatorname{tcbCC}>\mathrm{CeO}_{2}>\mathrm{CuO}$ ) in this work is inconsistent with the catalytic activity result, as shown in Table S1, Figs. 5A and 7. For example, the copCC sample possesses the best reducibility, while the catalytic activity of $\operatorname{copCC}\left(T_{90}=255^{\circ} \mathrm{C}\right)$ is much lower than that of the $\operatorname{strCC} 15\left(T_{90}=215^{\circ} \mathrm{C}\right)$. That is to say, the redox property of prepared catalysts is probably not the most vital factor determining the overall catalytic activity, and propanal oxidation over synthesized catalysts should obeys the suprafacial mechanism. The $\mathrm{O} 1 \mathrm{~s}$ XPS and $\mathrm{H}_{2}$-TPR results reveal that the mesoporous $\mathrm{CuCeO}_{2-\delta}$ catalysts possess higher surface oxygen concentrations (relevant to the oxygen vacancy density) than those of copCC, impCC, and tcbCC samples (Table 2, Figs. 5 and 6). In addition, the large specific surface area favors the dispersion of active phase, and hence promotes the catalytic process. The relations between $T_{90}$ and surface oxygen concentration and specific surface area for all composite catalysts were studied (Fig. 7D). General linear relations of $T_{90}$ versus $\mathrm{O}_{\text {surf }}$ content and $T_{90}$ versus specific surface area could be established, namely, the temperatures of $T_{90}$ increase with the decrease of $\mathrm{O}_{\text {surf }}$ concentration and specific surface area. Therefore, we can anticipate that the specific surface area and surface oxygen density are two foremost factors governing the catalytic activity.

\section{Conclusions}

Mesoporous $\mathrm{CuCeO}_{2-\delta}$ composites with high specific surface area and developed mesoporosity were prepared by a low cost and effective metal cation chelating method with modified maize starch as the bio-template. The experimental results shows that all $\operatorname{strCC} x$ samples have shaggy and flake-like morphology. Large portion of $\mathrm{Cu}^{x+}$ ions are incorporated into $\mathrm{CeO}_{2}$ lattice, which leads to structure defects and improved oxygen mobility. $\mathrm{Cu}$ species is well-dispersed in strCC15 and copCC samples, while the aggregation of $\mathrm{Cu}$ species can be found over tcbCC and strCC40. The catalyst reducibility is not the primary factor determining the catalytic performance. The strCC15 possesses the highest propanal destruction activity (reaction rate is 19.9 times higher than tcbCC at $225^{\circ} \mathrm{C}$ ), and propanal can be totally removed at $230^{\circ} \mathrm{C}$. In general, the superior activity of $\operatorname{strCC} x$ catalysts is ascribed to their large specific surface area and high surface oxygen concentration. We proposes that this protocol based on electrostatic attraction is a universal route for preparing mesostructured metal oxides with single or multiple components, which should have vast application prospects in catalysis, adsorption, separation processes.

\section{Acknowledgments}

Financial supports of the National Natural Science Foundation (21477095, 21107106), the Postdoctoral Science Foundation of China (2014M550498), and the Postdoctoral Science Foundation of Shaanxi Province are gratefully acknowledged. Dr. Lirong Zheng in Beijing Synchroton Radiation Facility (BSRF, China) is acknowledged for the XAFS analysis. The authors are also grateful to the reviewers and the editor for their helpful comments.

\section{Appendix A. Supplementary material}

Supplementary data associated with this article can be found, in the online version, at http://dx.doi.org/10.1016/j.jcis.2015.05.021.

\section{References}

[1] S.S. Wang, L. Zhang, C. Long, A.M. Li, J. Colloid Interface Sci. 428 (2014) 185190.

[2] C. He, Y.K. Yu, L. Yue, N.L. Qiao, J.J. Li, Q. Shen, W.J. Yu, J.S. Chen, Z.P. Hao, Appl. Catal. B: Environ. 147 (2014) 156-166.

[3] C.B. Zhang, Y.B. Li, Y.F. Wang, H. He, Environ. Sci. Technol. 48 (2014) 58165822.

[4] X.Y. Wang, L. Ran, Y. Dai, Y.J. Lu, Q.G. Dao, J. Colloid Interface Sci. 426 (2014) 324-332.

[5] S. Subramanian, G. Pande, G. De Weireld, J.-M. Giraudon, J.-F. Lamonier, V.S. Batra, Ind. Corp. Prod. 49 (2013) 108-116.

[6] V.D. Araújo, J.D.A. Bellido, M.I.B. Bernardi, J.M. Assaf, E.M. Assaf, Int. J. Hydrogen Energy 37 (2012) 5498-5507.

[7] P. Ratnasamy, D. Srinivas, C.V.V. Satyanarayana, P. Manikandan, R.S.S. Kumaran, M. Sachin, V.N. Shetti, J. Catal. 221 (2004) 455-465.

[8] X. Chen, S.A.C. Carabineiro, S.S.T. Bastos, P.B. Tavares, J.J.M. Órfão, M.F.R Pereira, J.L. Figueiredo, Appl. Catal. A: Gen. 472 (2014) 101-112.

[9] X.Y. Wang, Q. Kang, D. Li, Appl. Catal. B: Environ. 86 (2009) 166-175.

[10] S.D. Jackson, J.S.J. Hargreaves, Wiley-VCH Verlag GmbH \& Co. KGaA, Weinheim, 2009.

[11] H.Y. Zhu, J.-C. Zhao, J.W. Liu, X.Z. Yang, Y.N. Shen, Chem. Mater. 18 (2006) 3393-4001.

[12] J.L. Wu, Q.B. Xia, H.H. Wang, Z. Li, Appl. Catal. B: Environ. 156-157 (2014) 265 272.

[13] U. Menon, H. Poelman, V. Bliznuk, V.V. Galvita, D. Poelman, G.B. Marin, J. Catal. 295 (2012) 91-103.

[14] B. de Rivas, C. Sampedro, E.V. Ramos-Fernandez, R. Lopez-Fonseca, J. Gascon, M. Makkee, J.I. Gutierrez-Ortiz, Appl. Catal. A: Gen. 456 (2013) 96-104.

[15] M. Popova, A. Ristić, V. Mavrodinova, D. Maučec, L. Mindizova, N. Novak Tušar, Catal. Lett. 144 (2014) 1096-1100.

[16] F. Jiao, J.-C. Jumas, M. Womes, A.V. Chadwick, A. Harrison, P.G. Bruce, J. Am. Chem. Soc. 128 (2006) 12905-12909.

[17] Y. Ren, Z. Ma, P.G. Bruce, Chem. Soc. Rev. 41 (2012) 4909-4927.

[18] H.O. Jacobs, G.M. Whitesides, Science 291 (2001) 1763-1766.

[19] B.Z. Tian, X.Y. Liu, H.F. Yang, S.H. Xie, C.Z. Yu, B. Tu, D.Y. Zhao, Adv. Mater. 15 (2003) 1370-1374.

[20] A. Arango-Diaz, E. Moretti, A. Talon, L. Storaro, M. Lenarda, P. Nunez, J Marrero-Jerez, J. Jimenez-Jimenez, A. Jimenez-Lopez, E. Rodriguez-Castellon, Appl. Catal. A: Gen. 477 (2014) 54-63.

[21] M.I. Dominguez, A. Perez, M.A. Centeno, J.A. Odriozola, Appl. Catal. A: Gen. 478 (2014) 45-57.

[22] Q. Hua, T. Cao, X.-K. Gu, J.Q. Lu, Z.Q. Jiang, X.R. Pan, L.F. Luo, W.X. Li, W.X. Huang, Angew. Chem. Int. Ed. 53 (2014) 4856-4861.

[23] B. Levasseur, S. Kaliaguine, Appl. Catal. B: Environ. 88 (2009) 305-314.

[24] Z. Wu, M. Li, J. Howe, H.M. Meyer, S.H. Overbury, Langmuir 26 (2010) 1659516606.

[25] M.-F. Luo, J.-M. Ma, J.-Q. Lu, Y.-P. Song, Y.-J. Wang, J. Catal. 246 (2007) 52-59.

[26] B. de Rivas, C. Sampedro, M. García-Real, R. López-Fonseca, J.I. Gutiérrez-Ortiz, Appl. Catal. B: Environ. 129 (2013) 225-235.

[27] C.Q. Hu, Q.S. Zhu, Z. Jiang, Y.Y. Zhang, Y. Wang, Micropor. Mesopor. Mater. 113 (2008) 427-434

[28] C. He, Y.K. Yu, C.W. Chen, L. Yue, N.L. Qiao, Q. Shen, J.S. Chen, Z.P. Hao, RSC Adv. 3 (2013) 19639-19656.

[29] Y. Chen, J. Cao, M. Zheng, X. Ke, H. Ji, J. Liu, et al., Chem. Lett. 35 (2006) $702-$ 703.

[30] A. Taubert, G. Wegner, J. Mater. Chem. 12 (2002) 805-807.

[31] A.A. Aly, Starch/Stärke 58 (2006) 391-400.

[32] R.M. Cheng, S.J. Ou, B. Xiang, Y.J. Li, Q.Q. Liao, J. Polym. Res. 16 (2009) 703-708.

[33] H. Cölfen, Q. Limin, Chem. Eur. J. 7 (2001) 106-116.

[34] J.M. Marentette, J. Norwig, E. Stöckelmann, W.H. Meyer, G. Wegner, Adv. Mater. 9 (1997) 647-651.

[35] M.I. Khalil, A.A. Aly, Starch/Stärke 50 (1998) 267-271.

[36] D.K. Kweon, J.K. Choi, E.K. Kim, S.T. Lin, Carbohydr. Polym. 46 (2001) 171-177.

[37] R. Dziembaj, M. Molenda, L. Chmielarz, M.M. Zaitz, Z. Piwowarska, A. RafalskaŁasocha, Catal. Today 169 (2011) 112-117.

[38] P. Li, C. He, J. Cheng, C.Y. Ma, B.J. Dou, Z.P. Hao, Appl. Catal. B: Environ. 101 (2011) 570-579.

[39] S. Mukherjee, M.A. Vannice, J. Catal. 243 (2006) 108-130.

[40] L. Guo, Y. Zhu, X.F. Du, Starch/Stärke 64 (2012) 552-562.

[41] H.F. Yang, D.Y. Zhao, J. Mater. Chem. 15 (2005) 1217-1231.

[42] W.J. Shan, W.J. Shen, C. Li, Chem. Mater. 15 (2003) 4761-4767. 
[43] M.A. Camblor, A. Corma, S. Valencia, Micropor. Mesopor. Mater. 25 (1998) 5974.

[44] C. He, F.W. Zhang, L. Yue, X.S. Shang, J.S. Chen, Z.P. Hao, Appl. Catal. B: Environ. 111-112 (2012) 46-57.

[45] I. Platzman, R. Brener, H. Haick, R. Tannenbaum, J. Phys. Chem. C 112 (2008) $1101-1108$

[46] H. Praliaud, S. Michailenko, Z. Chajar, Z.M. Primet, Appl. Catal. B: Environ. 16 (1998) 359-374.

[47] D. Gamarra, G. Munuera, A.B. Hungría, M. Fernández-García, J.C. Conesa, P.A. Midgley, J.C. Hanson, J.A. Rodríguez, A. Martínez-Arias, J. Phys. Chem. C 111 (2007) 11026-11038.

[48] R. López-Fonseca, A. Aranzabal, P. Steltenpohl, J.I. Gutiérrez-Ortiz, J.R. González-Velasco, Catal. Today 62 (2000) 367-377.
[49] M. Baldi, V.S. Escribano, J.M.G. Amores, F. Milella, G. Busca, Appl. Catal. B: Environ. 17 (1998) L175-L182.

[50] Z.-Q. Zou, M. Meng, Y.Q. Zha, J. Phys. Chem. C 114 (2010) 468-477.

[51] S.C. Kim, W.G. Shim, Appl. Catal. B: Environ. 98 (2010) 180-185.

[52] C.Y. Chen, J. Zhu, F. Chen, X.J. Meng, X.M. Zheng, X.H. Gao, F.-S. Xiao, Appl. Catal. B: Environ. 140-141 (2013) 199-205.

[53] R.J.H. Voorhoeve, J.P. Remika, D.W. Johnson, Science 180 (1973) 62-64.

[54] R.H. Wang, J.H. Li, Environ. Sci. Technol. 44 (2010) 4282-4287.

[55] V.P. Santos, M.F.R. Pereira, J.J.M. Órfão, J.L. Figueiredo, Appl. Catal. B: Environ. 99 (2010) 353-363.

[56] L.F. Liotta, M. Ousmane, G. Di Carlo, G. Pantaleo, G. Deganello, G. Marcì, L. Retailleau, A. Giroir-Fendler, Appl. Catal. A: Gen. 347 (2008) 81-88. 